\title{
Variability Predictors of Vasospasm in Subarachnoid Hemorrhage: A Feasibility Study
}

\author{
Rosendo A. Rodriguez (D), Christophe L. Herry, Shane W. English, Tim Ramsay, \\ Andrew J.E. Seely, Glen P. Kenny, Michel Shamy (1D
}

\begin{abstract}
Background: Mean cerebral blood flow velocity (mean-CBFV) obtained from Transcranial Doppler (TCD) poorly predicts cerebral vasospasm in patients with aneurysmal subarachnoid hemorrhage (aSAH). Variability descriptors of mean-CBFV obtained during extended TCD recordings may improve this prediction. We assessed the feasibility of generating reliable linear and nonlinear descriptors of mean-CBFV variability using extended recordings in aSAH patients and in healthy controls. We also explored which of those metrics might have the ability to discriminate between aSAH patients and healthy controls, and among patients who would go on to develop vasospasm and those who would not. Methods: Bilateral mean-CBFV, blood pressure, and heart rate were continuously recorded for 40 minutes in aSAH patients $(\mathrm{n}=8)$ within the first 5 days after ictus, in age-matched healthy controls $(\mathrm{n}=8)$ and in additional young controls $(\mathrm{n}=8)$. We obtained linear [standard deviation, coefficient of variations, and the very-low $(0.003-0.040 \mathrm{~Hz})$, low $(0.040-0.150 \mathrm{~Hz})$, and high-frequency $(0.15-0.4 \mathrm{~Hz})$ power spectra] and non-linear (Fractality, deterministic Chaos analyses) variability metrics. Results: We successfully obtained TCD recordings from patients and healthy controls and calculated the desired metrics of mean-CBFV variability. Differences were appreciable between aSAH patients and healthy controls, as well as between aSAH patients who later developed vasospasm and those who did not. Conclusions: A 40-minute TCD recording provides reliable variability metrics in aSAH patients and healthy controls. Future studies are required to determine if mean-CBFV variability metrics remain stable over time, and whether they may serve to identify patients who are at greatest risk of developing cerebral vasospasm after aSAH.
\end{abstract}

RÉSUMÉ : Les prédicteurs de variabilité d'un vasospasme dans des cas d'hémorragie sous-arachnoïdienne avec anévrisme : une étude de faisabilité. Contexte : La vitesse moyenne du débit sanguin cérébral (VMDSC) obtenue à partir d'une échographie Doppler (ED) ne parvient pas à bien prédire un vasospasme cérébral dans le cas de patients victimes d'hémorragie sous-arachnoïdienne avec anévrisme (HSAa). Cela dit, des descripteurs de la variabilité de la VMDSC obtenue à l'occasion d'ED d'une durée prolongée pourraient quand même améliorer cette prédiction. Nous avons donc cherché à évaluer la possibilité de produire des descripteurs linéaires et non-linéaires fiables de la variabilité de la VMDSC au moyen d'ED prolongées chez des patients victimes d'HSAa et des témoins en santé. Nous avons également cherché à savoir lequel ou lesquels de ces descripteurs pourraient avoir la capacité d'établir une distinction entre, d'une part, des patients victimes d'HSAa et des témoins en santé et, d'autre part, entre des patients développant par la suite un vasospasme et d'autres non. Méthodes : Dans les 5 premiers jours suivant un ictus, la VMDSC bilatérale, la tension artérielle et la fréquence cardiaque ont été enregistrées en continu pendant 40 minutes chez des patients victimes d'HSAa $(\mathrm{n}=8)$ mais aussi chez des témoins en santé du même âge $(\mathrm{n}=8)$ et des témoins plus jeunes $(\mathrm{n}=8)$. Du coup, nous avons pu obtenir des paramètres de variabilité linéaires [écart-type, coefficient des variations, densité spectrale de puissance de très faible intensité $(0,003-0,040 \mathrm{~Hz})$, de faible intensité $(0,040-0,150 \mathrm{~Hz})$ et d'intensité élevée $(0,15-0,4 \mathrm{~Hz})]$ et nonlinéaires (analyse fractale et analyses déterministes du chaos). Résultats : Nous avons obtenu avec succès des résultats d'ED auprès de patients et de témoins en santé. Nous avons aussi été en mesure de calculer les descripteurs appropriés de la variabilité de la VMDSC. Des différences appréciables entre les patients victimes d'HSAa et les témoins en santé ont émergé de même qu'entre des patients ayant développé ultérieurement un vasospasme et d'autres non. Conclusions : Il ressort donc qu'une ED de 40 minutes peut permettre d'obtenir des descripteurs fiables chez des patients victimes d'HSAa et des témoins en santé. Ceci dit, de futures études sont nécessaires pour déterminer si les descripteurs de la variabilité de la VMDSC demeurent stables au fil du temps et aussi dans quelle mesure ils pourraient permettre d'identifier les patients les plus exposés au risque de développer un vasospasme à la suite d'une HSAa.

Keywords: Transcranial Doppler sonography, Subarachnoid hemorrhage, Intracranial vasospasm, Entropy, Fourier analysis doi:10.1017/cjn.2020.157

Can J Neurol Sci. 2021; 48: 226-232

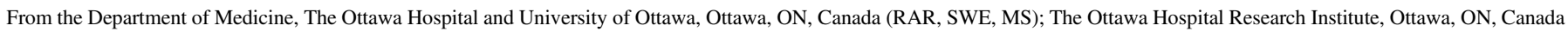

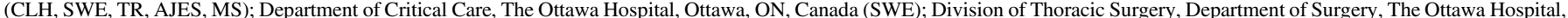

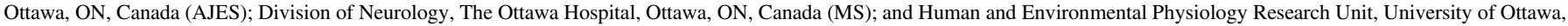
Ottawa, ON, Canada (GPK)

Received January 29, 2020. Final Revisions Submitted June 25, 2020. Date of Acceptance July 13, 2020.

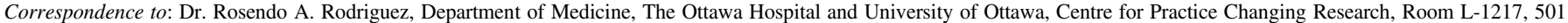

Smyth Road, Ottawa, Ontario, Canada K1H 8L6. Email: rrodriguez@toh.ca 


\section{BACKGROUND}

Patients with aneurysmal subarachnoid hemorrhage (aSAH) are at risk of developing vasospasm and delayed cerebral ischemia. ${ }^{1-4}$ Standard measurements of cerebral blood flow velocity with Transcranial Doppler (TCD) struggle to predict these complications, likely because standard TCD offers only a snapshot of a dynamic disease process. Increasing attention has been directed toward investigating the role of variability in cerebral blood flow velocity as a predictor of vasospasm in aSAH. ${ }^{5}$ Both linear and non-linear descriptors of variability have been investigated in this context. ${ }^{5}$ Linear metrics, such as standard deviations, averages, and total power spectra values, have shown limited predictive accuracy, likely as a consequence of the multiple factors that influence cerebral perfusion over time, including systemic blood pressure, respiratory rate, arterial content of carbon dioxide $\left(\mathrm{PCO}_{2}\right)$, cardiac output, hematocrit, and cerebral metabolism. ${ }^{6-8}$ Non-linear descriptors such as the use of fractal and chaotic characteristics of cerebral blood flow velocity may better predict vasospasm ${ }^{7}$ though it is not clear which metrics might have the best predictive capabilities. ${ }^{5,9-11}$ Moreover, it remains unclear if it is feasible to perform TCD recordings that would reliably generate linear and non-linear estimates of variability under routine clinical conditions. In this feasibility study, we sought to determine whether we could perform adequate TCD recordings to assess a series of linear and non-linear metrics of cerebral blood flow variability in patients with aSAH as well as in healthy controls. We also explored which metrics might have the ability to assess differences in variability between aSAH patients and healthy controls, and among patients who would go on to develop vasospasm and those who would not. We selected a comprehensive set of variability descriptors (see Supplementary Table S-1) in the time and frequency domains as well as non-linear indices of fractality and deterministic chaos that have been investigated previously. $5,7,12-15$

\section{MethodS}

The study was approved by The Ottawa Health Science Network Research Ethics Board and conforms to the principles outlined in the Declaration of Helsinki. Our study was cross sectional, and it was guided according to the STROBE statement on observational studies. Written informed consent was obtained from participants or their substitute decision-makers.

\section{Study Planning}

We initially reviewed the available literature and identified a set of linear and non-linear metrics of variability (see Supplementary Table S-1). ${ }^{5,15}$ Linear analyses included traditional time-domain techniques such as the calculation of standard deviations and coefficient of variations..$^{5,8,12,18}$ Non-linear methods of analysis included Fractality measures [Hurst coefficient, ${ }^{5,7}$ Fractal dimension, ${ }^{13,14}$ and Higuchi exponent ${ }^{19}$ ] and descriptors of deterministic chaos [correlation dimension $\left(D_{2}\right)^{9,20-22}$ and maximum Lyapunov exponent $(\lambda)] .{ }^{10,11,15}$ In the frequency domain, we sought to calculate the power spectrum for the very-low-frequency $(0.003-0.040 \mathrm{~Hz})$, low-frequency $(0.040-$ $0.150 \mathrm{~Hz})$, and high-frequency $(0.15-0.4 \mathrm{~Hz})$ ranges derived from the mean flow velocity, pulsatility index and mean systemic blood pressure. ${ }^{7,8}$ Four durations of recordings $(25,30,40$, and
45 minutes) were tested by two of the authors (RAR, CLH) to determine which would provide sufficient data to calculate the metrics of interest. It was concluded that a 40-minute recording was the minimal recording that would provide the necessary data.

\section{Population}

\section{aSAH group}

We enrolled consecutive adult patients ( $>18$ years) with a clinical and radiographic ${ }^{23}$ diagnosis of aSAH (Fisher scale $\geq 2$ ) within the first 5 days of their ictus and who were admitted to the Intensive Care Unit (ICU) of the Civic Campus, The Ottawa Hospital, between January and November 2018. Patients with traumatic aSAH or with other unrelated central neurologic disorders, active infection or sepsis, additional bleeding disorders, or hemodynamic instability for other reasons were excluded. Patients were treated according to a standard clinical protocol for aSAH with the purpose of maintaining cerebral perfusion pressure and to prevent secondary ischemia related to vasospasm. None of the patients with aSAH were known to have vasospasm at the time of recording. All participants received routine monitoring of vital signs, intensive nursing care, and routine assessment of their neurologic status including the Glasgow Coma Scale (GCS) at admission and during their stay in the ICU. ${ }^{24}$ Aneurysms were clipped surgically or coiled endovascularly according to the preferences of the treating team.

\section{Healthy Controls}

To determine whether these metrics of variability might have the ability to distinguish deviations from normality in aSAH patients, a healthy population was identified as a control group by assessing their wellness status using a self-reporting health questionnaire. Thus, staff volunteers from our institution were invited to participate as control subjects. Two control groups were planned a priori. The first group included students and young staff under 40 years of age (young healthy controls), and the second group comprised of older healthy subjects who were matched according to their age with the aSAH group (agematched healthy controls).

\section{Monitoring Procedure}

Two $2 \mathrm{MHz}$ pulse-wave Doppler probes were secured on the temporal area to simultaneously monitor cerebral blood flow velocity from the right and left middle cerebral arteries (MCAs) using the ST3 digital Transcranial Doppler (TCD) system (Model PMD150; Spencer Technologies, Redmond, WA). The envelopes of the Doppler spectra waveform corresponding to the peak, mean, and diastolic flow velocities were exported from the TCD system and analyzed with a custom-designed software program (CIMVA executable, Version 4.6, OHRI Dynamic Analysis Laboratory). Systemic blood pressure was also continuously recorded from the radial artery in all aSAH participants. In all age-matched controls and in two of the young controls, noninvasive continuous recording of blood pressure from the finger was obtained by photoplethysmography ${ }^{25}$ using a Finometer (Finapres Medical Systems, Enschede, The Netherlands). The Finometer was calibrated using upper arm return-to-flow systolic pressure detection and physical criteria following brachial artery 
pressure reconstruction. ${ }^{26}$ Heart rate from an electrocardiogram was monitored in all participants. Continuous TCD recordings lasted approximately 40 minutes. Measurements for aSAH patients were performed at the bedside while for controls, recordings were performed in an isolated room, in the supine position, with the head elevated to $30^{\circ}$, and with the subjects awake or in physiological light sleep. All TCD recordings in the young control group were performed in the morning (10:0011:00 am). In the age-matched controls, however, we accommodated morning (10:00 am to noon) and afternoon sessions (13:00-15:00 hours). No complications were identified during any of the recording sessions.

\section{Follow-Up}

Determination of vasospasm was extracted from the patient chart at the time of discharge, and the assessor for this outcome was blinded to the study results. We relied upon the indices used by the clinical teams: namely, evidence of cerebral vasospasm determined by CT/MRI angiography (narrowing of the vascular segment of at least one-third of its diameter) ${ }^{27}$ or by TCD examination (mean flow velocity $>120 \mathrm{~cm} / \mathrm{s}$ ). ${ }^{28}$ The angiographic definition of vessel narrowing sufficient to be considered cerebral vasospasm was established without consideration of the clinical manifestations of delayed cerebral ischemia. ${ }^{29}$ Data collected for the purposes of this feasibility study were not made available to treating physicians and, therefore, did not impact any diagnostic or therapeutic decision-making.

\section{Outcome Measures}

Primary feasibility outcomes were the proportion of completed TCD recordings in both aSAH patients and healthy controls as well as the proportion of TCD recordings that provided acceptable time-series estimates to calculate linear and non-linear variability metrics. Secondarily, we determined differences in the proposed set of linear and non-linear indices of variability for the mean blood flow velocity, mean systemic blood pressure, and TCD pulsatility index between the aSAH group (including those with and without vasospasm) and the control groups. In calculating these between-group differences, we hoped to identify the best indices of variability that would discriminate between these two populations.

\section{Data Processing and Analysis}

All TCD and mean arterial pressure waveforms were visually inspected for artifacts. Only artifact-free data were included in the analyses. Data analysis was performed by an independent observer who was not aware of the clinical characteristics of aSAH participants. Separate time-averaged values for all indices of variability were obtained from a minimum of three artifact-free overlapping windows with 1800 beats each. From this analysis, we calculated separate variability indices for the cerebral blood flow velocity, pulsatility index, and mean systemic blood pressure (see Supplementary Table S-1). The pulsatility index was calculated as the difference between the systolic and diastolic flow velocity divided by the mean flow velocity. ${ }^{30}$

\section{Statistical Analysis}

Data are reported as means, standard deviations, or their $95 \%$ confidence intervals $(95 \% \mathrm{CI})$. Discrete variables are expressed in absolute values and percentages. To describe each population, variability data were averaged across patients. Due to the feasibility nature of our primary outcome, expected small sample size, and exploratory character of the between-group differences, we did not attempt to perform any statistical analyses, and all comparative observations were reported descriptively.

\section{RESULTS \\ Demographics and Clinical Data}

We included eight patients with aSAH (age: $58 \pm 10$ years; two females; range: 44-74 years), eight young healthy controls (age: $26 \pm 5$ years; four females; range: $21-31$ years), and eight agematched healthy controls (age: $57 \pm 10$; one female; range: $40-72$ years). In the aSAH group, the mean GCS at admission was $10 \pm 4$, and the average time from admission to the TCD examination was $4 \pm 1$ days. Of the patients with aSAH, three developed cerebral vasospasm according to our criteria. At the time of recording, none of the aSAH patients had a definitive clinical diagnosis of vasospasm, and the interval between the TCD examination and a confirmed diagnosis varied from 48 to 72 hours. One patient died of heart failure; most of the survivors except one were discharged with at least one neurologic sequela (Table 1).

\section{Feasibility Outcomes}

Bilateral extended TCD recordings were successfully completed in all aSAH patients and control subjects. Consent was provided by a substitute decision-maker in all patients, and by the participant for healthy controls. Two eligible patients declined enrollment. No enrolled subject or patient sought to opt out of the study. The average duration for the recording session in the aSAH, age-matched, and young control groups was $40 \pm 6$, $44 \pm 3$, and $41 \pm 2$ minutes, respectively. All individual TCD recordings provided at least three artifact-free overlapping windows of 1800 beats, which were sufficient to calculate reliable linear and non-linear metrics of variability for every participant.

\section{Exploratory Outcomes}

Among the metrics assessed, the correlation dimension (Table 2), an indicator of the complexity of physiologic signals, was higher in aSAH patients than in both control groups. aSAH patients also showed higher pulsatility indices, greater high-frequency spectral power, and decreased very-low-frequency spectral power in the mean blood flow velocity relative to healthy controls (see Table 2). Variability metrics for the pulsatility index did not show noticeable differences among the three groups (Supplementary Table S-2). aSAH patients had higher mean systemic blood pressures, low spectral power in the very-low frequencies, and reduced fractal dimension in the systemic blood pressure compared to age-matched controls (Table 3). aSAH patients who developed vasospasm showed higher mean MCA blood flow velocities, smaller pulsatility indices, and lower coefficient of variations in the MCA mean blood flow velocity compared to those who did not develop vasospasm (Table 4). Finally, there were no observable differences in variability between the control groups that would suggest any age-related effects (see Table 2).

\section{Discussion}

Our findings indicate that it is feasible to perform a 40-minute TCD recording to obtain linear and non-linear metrics of 
Table 1: Demographics, clinical features, and evolution of participants in the aSAH group

\begin{tabular}{l|l|c|c|l|l|l}
\hline $\begin{array}{l}\text { Age } \\
\text { (years) }\end{array}$ & Gender & $\begin{array}{c}\text { GCS at } \\
\text { arrival }\end{array}$ & $\begin{array}{c}\text { TCD } \\
\text { examination } \\
\text { (days)* }\end{array}$ & $\begin{array}{c}\text { Anatomical site of ruptured } \\
\text { aneurysm }\end{array}$ & Clinical diagnosis of vasospasm & Neurologic deficits at discharge \\
\hline 57 & Male & 7 & 3 & Right posterior communicating artery & None & Left hemiplegia \\
\hline 64 & Female & 7 & 3 & $\begin{array}{l}\text { Anterior communicating artery; acute } \\
\text { left PCA infarct }\end{array}$ & $\begin{array}{l}\text { Left ACA aneurysm and mild left } \\
\text { MCA }\end{array}$ & Cognitive deficits \\
\hline 74 & Female & 8 & 5 & Left anterior communicating artery & None & Death; heart failure \\
\hline 63 & Male & 12 & 5 & $\begin{array}{l}\text { Anterior communicating artery; right } \\
\text { frontal IVH (Fisher 4) }\end{array}$ & $\begin{array}{l}\text { Bilateral ACA, partial involvement of } \\
\text { right MCA }\end{array}$ & $\begin{array}{l}\text { Left hemiparesis mild cognitive } \\
\text { impairment }\end{array}$ \\
\hline 44 & Male & 15 & 5 & $\begin{array}{l}\text { Anterior communicating artery; right } \\
\text { frontal lobe intraparenchymal bleeding }\end{array}$ & $\begin{array}{l}\text { Multi-segmental bilateral ACA and } \\
\text { MCA with residual right MCA } \\
\text { vasospasm }\end{array}$ & $\begin{array}{l}\text { Cognitive deficits: executive, memory, } \\
\text { and attention-deficit disorders }\end{array}$ \\
\hline 62 & Male & 10 & 3 & Dissecting vertebral aneurysm & None & Cognitive deficits \\
\hline 46 & Male & 15 & 3 & Left MCA & None & No evidence of neurologic deficits \\
\hline 61 & Female & 14 & 3 & Basilar/SCA junction & Paralysis VI nerve \\
\hline
\end{tabular}

*Date of examination: in days relative to the time of admission; aSAH = aneurysmal Subarachnoid Hemorrhage; GCS = Glasgow Coma Scale score; PCA = posterior cerebral artery; ACA = anterior cerebral artery; IVH = Intraventricular hemorrhage; $\mathrm{MCA}=$ middle cerebral artery; SCA = superior cerebellar artery; TCD $=$ Transcranial Doppler.

Table 2: Linear and non-linear indices of variability for the mean CBFV in the aneurysmal SAH group and in the two healthy control groups. Data represent combined values from the right and left MCAs for each patient. Values are reported as the means and their $95 \%$ confidence intervals

\begin{tabular}{l|c|c|c}
\hline & Aneurysmal SAH group & Age-matched healthy control group & Young healthy control group \\
\hline \multicolumn{5}{|c|}{ Linear measures } \\
\hline Mean CBFV $(\mathrm{cm} / \mathrm{s})$ & $59.2(47.5 ; 70.8)$ & $50.5(43.6 ; 57.4))$ & $58.5(49.0 ; 68.1)$ \\
\hline Pulsatility index & $0.9872(0.827 ; 1.148)$ & $0.802(0.721 ; 0.885)$ & $0.758(0.720 ; 0.797)$ \\
\hline Standard deviation & $38.6(31.4 ; 45.8)$ & $36.1(26.9 ; 45.2)$ & $39.9(29.8 ; 50.0)$ \\
\hline Coefficient of variation $(\%)$ & $7.1(5.5 ; 8.8)$ & $7.1(5.9 ; 8.3)$ & $6.6(5.6 ; 7.7)$ \\
\hline $\begin{array}{l}\text { Very-low-frequency spectral } \\
\text { power }\left(\mathrm{cm}^{2}\right)^{* *}\end{array}$ & $0.191(0.137 ; 0.245)$ & $0.261(0.214 ; 0.309)$ & $0.238(0.204 ; 0.273)$ \\
\hline Low-frequency spectral power $\left(\mathrm{cm}^{2}\right) * * *$ & $0.105(0.058 ; 0.153)$ & $0.101(0.075 ; 0.126)$ & $0.105(0.088 ; 0.122)$ \\
\hline $\begin{array}{l}\text { High-frequency spectral } \\
\text { power }\left(\mathrm{cm}^{2}\right)^{* * * *}\end{array}$ & $0.109(0.077 ; 0.141)$ & $0.056(0.026 ; 0.087)$ & $0.046(0.027 ; 0.066)$ \\
\hline \multicolumn{2}{|c|}{ Non-linear measures } & \\
\hline Hurst exponent & & $0.464(0.252 ; 0.677)$ & $1.536(1.324 ; 1.748)$ \\
\hline Fractal dimension & $0.419(0.264 ; 0.575)$ & $2.003(1.960 ; 2.046)$ & $0.475(0.267 ; 0.683)$ \\
\hline Higuchi exponent & $1.58(1.425 ; 1.735)$ & $6.938(5.802 ; 8.147)$ & $1.525(1.317 ; 1.733)$ \\
\hline Correlation Dimension $\left(\mathrm{D}_{2}\right)$ & $1.969(1.946 ; 1.993)$ & $0.037(0.025 ; 0.049)$ & $2.001(1.982 ; 2.019)$ \\
\hline Largest Lyapunov exponent $(\lambda)$ & $8.67(7.674 ; 9.664)$ & $6.603(5.425 ; 7.782)$ \\
\hline
\end{tabular}

$\mathrm{CBFV}=$ cerebral blood flow velocity; $\mathrm{MCA}=$ middle cerebral artery; $\mathrm{SAH}=$ subarachnoid hemorrhage; **Very-low-frequency band: $0.003-0.040 \mathrm{~Hz}$; *** Low-frequency band: $0.040-0.15 \mathrm{~Hz}$; ****High-frequency band: $0.15-0.40 \mathrm{~Hz}$.

variability from cerebral blood flow velocity in patients with aSAH and healthy controls. Our exploratory analysis suggested that several parameters including the correlation dimension, pulsatility index, the spectral power of the very-low and highfrequency bands, and the coefficient of variation may be helpful to differentiate patients with aSAH and healthy controls and between those with and without vasospasm. A potential explanation for these findings, if they are confirmed in larger studies, is that the complexity of the system that regulates cerebral blood flow may be greater in patients with aSAH than in healthy individuals, and that the progression to cerebral vasospasm diminishes this complexity by decreasing the variability of cerebral blood flow. ${ }^{5,12,20}$ Moreover, aSAH patients showed reduced spectral power in the very-low-frequency area 
Table 3: Linear and non-linear indices of variability for the mean arterial blood pressure in the aSAH group and the age-matched healthy control group. Values are reported as the means and their $95 \%$ confidence interval

\begin{tabular}{l|c|c}
\hline & Subarachnoid hemorrhage group & Age-matched healthy control group* \\
\hline \multicolumn{2}{|c|}{ Linear measures } \\
\hline MAP $(\mathrm{mm} \mathrm{Hg})$ & $105.0(94 ; 116)$ & $93.5(88 ; 99)$ \\
\hline Standard deviation & $6.2(4.2 ; 8.2)$ & $5.2(4.1 ; 6.4)$ \\
\hline Coefficient of variation $(\%)$ & $5.9(4.1 ; 7.7)$ & $5.6(4.5 ; 6.6)$ \\
\hline Very-low-frequency spectral power $\left(\mathrm{mm} \mathrm{Hg}^{2}\right)^{* *}$ & $0.123(0.047 ; 0.200)$ & $0.224(0.183 ; 0.265)$ \\
\hline Low-frequency spectral power $\left(\mathrm{mm} \mathrm{Hg}^{2}\right)^{* * *}$ & $0.117(0.026 ; 0.209)$ & $0.098(0.071 ; 0.124)$ \\
\hline High-frequency spectral power $\left(\mathrm{mm} \mathrm{Hg}^{2}\right)^{* * * *}$ & $0.138(0.089 ; 0.187)$ & $0.149(0.097 ; 0.200)$ \\
\hline & Non-linear measures \\
\hline Hurst exponent & $0.635(0.419 ; 0.871)$ & $0.046(0.034 ; 0.057)$ \\
\hline Fractal dimension & $1.364(1.149 ; 1.581)$ & $1.954(1.942 ; 1.965)$ \\
\hline Higuchi exponent & $1.976(1.950 ; 2.001)$ & $2.004(1.962 ; 2.047)$ \\
\hline Correlation Dimension $\left(\mathrm{D}_{2}\right)$ & $6.726(4.807 ; 8.645)$ & $5.603(5.040 ; 6.166)$ \\
\hline Largest Lyapunov exponent $(\lambda)$ & $0.089(0.041 ; 0.138)$ & $0.044(0.034 ; 0.053)$ \\
\hline
\end{tabular}

${ }^{\dagger}$ Mean arterial blood pressure recorded from the arterial line; *Blood pressure recordings were performed from the middle finger using the photoplethysmography Finapres technology; **Very-low-frequency band: $0.003-0.040 \mathrm{~Hz}$; ***Low-frequency band: $0.040-0.15 \mathrm{~Hz}$; ****Highfrequency band: $0.15-0.40 \mathrm{~Hz}$. aSAH = aneurysmal subarachnoid hemorrhage.

Table 4: Linear and non-linear variability indices for the mean cerebral blood flow velocity and mean arterial blood pressure between patients with aSAH who developed vasospasm compared to those without vasospasm. Data for the blood flow velocity in patients without vasospasm represent combined values from the right and left MCAs for each patient. In those with vasospasm, data values are separated according to the ipsilateral or contralateral side of vasospasm. Values are reported as mean \pm SD

\begin{tabular}{|c|c|c|c|c|c|}
\hline & \multicolumn{3}{|c|}{ Mean cerebral blood flow velocity $(\mathrm{cm} / \mathrm{s})$} & \multicolumn{2}{|c|}{ Mean arterial pressure $(\mathrm{mm} \mathbf{H g})$} \\
\hline & \multirow{2}{*}{$\begin{array}{l}\text { aSAH patients without } \\
\text { vasospasm }\end{array}$} & \multicolumn{2}{|c|}{ aSAH patients with vasospasm } & \multirow{2}{*}{$\begin{array}{l}\text { aSAH patients without } \\
\text { vasospasm }\end{array}$} & \multirow{2}{*}{$\begin{array}{l}\text { aSAH patients with } \\
\text { vasospasm }\end{array}$} \\
\hline & & Ipsilateral $^{\&}$ MCA & Contralateral MCA & & \\
\hline \multicolumn{6}{|c|}{ Linear measures } \\
\hline Average value & $48.1 \pm 16$ & $90 \pm 10$ & $60 \pm 29$ & $99 \pm 9$ & $122 \pm 4$ \\
\hline Pulsatility index & $1.10 \pm 0.34$ & $0.80 \pm 0.19$ & $0.79 \pm 0.19$ & $\mathrm{n} / \mathrm{a}$ & $\mathrm{n} / \mathrm{a}$ \\
\hline Standard deviation & $40.8 \pm 16.7$ & $41.1 \pm 8.7$ & $26.9 \pm 5.8$ & $5.95 \pm 2.74$ & $6.97 \pm 0.01$ \\
\hline Coefficient of variation $(\%)$ & $8.7 \pm 3.2$ & $4.7 \pm 1.2$ & $4.8 \pm 1.2$ & $5.95 \pm 2.5$ & $5.75 \pm 0.21$ \\
\hline $\begin{array}{c}\text { Very-low-frequency } \\
\text { power }\left(\mathrm{cm}^{2}\right)^{* *}\end{array}$ & $0.1953 \pm 0.1232$ & $0.1815 \pm 0.0972$ & $0.1860 \pm 0.0999$ & $0.1420 \pm 0.1013$ & $0.0690 \pm 0.0042$ \\
\hline $\begin{array}{l}\text { Low-frequency } \\
\text { power }\left(\mathrm{cm}^{2}\right)^{* * *}\end{array}$ & $0.1191 \pm 0.1206$ & $0.0875 \pm 0.0255$ & $0.0797 \pm 0.0353$ & $0.1313 \pm 0.1260$ & $0.0755 \pm 0.0010$ \\
\hline $\begin{array}{l}\text { High-frequency } \\
\text { power }\left(\mathrm{cm}^{2}\right)^{* * * *}\end{array}$ & $0.1061 \pm 0.0431$ & $0.1095 \pm 0.0920$ & $0.1220 \pm 0.1126$ & $0.1270 \pm 0.0556$ & $0.1740 \pm 0.0685$ \\
\hline \multicolumn{6}{|c|}{ Non-linear measures } \\
\hline Hurst exponent & $0.5134 \pm 0.3167$ & $0.2335 \pm 0.1615$ & $0.3243 \pm 0.3923$ & $0.5940 \pm 0.2769$ & $0.758 \pm 0.2043$ \\
\hline Fractal dimension & $1.4870 \pm 0.3167$ & $1.7665 \pm 0.1615$ & $1.6757 \pm 0.3923$ & $1.406 \pm 0.2769$ & $1.241 \pm 0.2043$ \\
\hline Higuchi exponent & $1.9800 \pm 0.0467$ & $1.9393 \pm 0.0451$ & $1.9697 \pm 0.0512$ & $1.976 \pm 0.0359$ & $1.976 \pm 0.0049$ \\
\hline Correlation dimension $\left(\mathrm{D}_{2}\right)$ & $8.8984 \pm 2.2733$ & $7.9932 \pm 1.8955$ & $8.7287 \pm 1.2588$ & $7.07 \pm 2.5160$ & $5.693 \pm 1.543$ \\
\hline $\begin{array}{l}\text { Largest Lyapunov } \\
\quad \text { exponent }(\lambda)\end{array}$ & $0.0504 \pm 0.0279$ & $0.0415 \pm 0.266$ & $0.0623 \pm 0.0225$ & $0.060 \pm 0.0191$ & $0.176 \pm 0.0410$ \\
\hline
\end{tabular}

aSAH: aneurysmal subarachnoid hemorrhage; MCA: middle cerebral artery; **Very-low-frequency band: $0.003-0.040$ Hz; ***Low-frequency band: $0.040-0.15 \mathrm{~Hz} ; * * * *$ High-frequency band: $0.15-0.40 \mathrm{~Hz} ; \mathrm{n} / \mathrm{a}=$ not applicable; ${ }^{\&}$ relative to the side of vasospasm. 
for both mean systemic blood pressure and mean cerebral blood flow velocity compared to healthy controls, though more so in systemic blood pressure than in cerebral blood flow velocity. This finding suggests that variability in cerebral blood flow in the verylow-frequency range may be partly dependent on variability in systemic blood pressure. ${ }^{17,31,32}$ Since the very-low frequencies represent the frequency range where cerebral autoregulation is expected to be most active, ${ }^{32}$ the dependence of cerebral blood flow on changes in systemic pressure could explain the vulnerability of aSAH patients to large fluctuations in systemic blood pressure.

\section{Methodological Considerations and Limitations}

We used high temporal resolution TCD ultrasound to measure beat-to-beat changes in blood flow velocity in the MCA, but this technique is based on measurements of blood flow velocity and not volumetric flow. ${ }^{7,33,34}$ Although we assumed that the diameter of the MCA remained relatively constant in normal subjects, we cannot ensure the same for aSAH patients due to the use of therapeutic agents aimed to maintain elevated systemic blood pressures. In age-matched controls, we measured changes in systemic blood pressure using finger plethysmography (i.e. Finometer), ${ }^{25}$ but this technique may not be the same as that obtained from intra-arterial pressure recordings in our aSAH patients admitted to the ICU. In addition, we recognize that our study was not powered to identify differences in variability indices. As a consequence, all of these results are reported descriptively. Although we recognize that performing 40-minute assessments repeatedly in critically ill patients may pose a logistical challenge under routine clinical conditions, an important consideration for future studies is the reproducibility of these variability metrics on repeated measurements and under controlled conditions. Moreover, several physiological variables that are well known to affect cerebral blood flow velocity, such as respiratory rate, hematocrit, $\mathrm{PCO}_{2}$, metabolic factors, and cardiac output, ${ }^{7,8,31}$ were not controlled in our study. Our decision to choose an age-matched healthy population as control group was based on our primary objective of feasibility to determine whether we would be able to provide adequate linear and non-linear metrics of variability. Given the known association of smoking and hypertension with aSAH ${ }^{35}$ an additional control group with these risk factors would have been clinically relevant as well. Despite our study identified differences in variability between young healthy males and females (see Supplementary Table S-3), sex-related effects were not accounted for in aSAH patients. We recognize that the choice of angiography as "gold standard" and our definition for the determination of cerebral artery vasospasm may be a limitation. The use of a different definition criterion or "gold standard" test could have modified the relationship between variability indices and the diagnosis of cerebral vasospasm in our patient population. Finally, the lack of a formal clinical assessment and/or brain imaging studies at the time of discharge precludes associating these indices of variability with clinical outcomes.

\section{Conclusions}

In summary, we determined that it was feasible to conduct extended TCD recordings for linear and non-linear metrics of cerebral blood flow velocity in healthy controls and patients with
aSAH. We were able to measure non-linear metrics, and identified a few specific measures (correlation dimension, coefficient of variation, pulsatility index, very-low and high-frequency spectral power) that are of interest for future studies as potential predictors of vasospasm in patients with aSAH. Further studies are necessary to confirm whether these metrics are reproducible and if any true relationship exists between variations in the complexity of the cerebral blood flow velocity of aSAH patients and their progression into vasospasm and/or poor clinical outcomes. If effective, sequential measurements of the beat-to-beat temporal variability in cerebral blood flow velocity and systemic blood pressure during relatively long periods (i.e. 40 minutes) in patients with aneurysmal SAH may impact risk stratification in patients with aSAH and guide interventions aimed to prevent delayed cerebral ischemia.

\section{ACKNowledgments}

The study was funded by the Clinical Research Award Program from the Department of Medicine, The Ottawa Hospital, and the University of Ottawa. We acknowledge Dr. Matthew Hogan from the Division of Neurology, The Ottawa Hospital, for his advice and feedback to this project and Robert Meade, from the Human and Environmental Physiology Research Unit of the University of Ottawa for his assistance during finger plethysmography and data extraction. The support from Brigette Gomes, Irene Watpool, Stephanie Belanger, staff nurses, physicians, and coordinators from the ICU and Clinical Investigative Unit, at The Ottawa Hospital, is gratefully appreciated. We thank the voluntary participation of patients, families, and staff.

\section{Statement of Authorship}

RAR and MS conceived and designed the study; RAR performed all TCD recordings and drafted the manuscript; CLH contributed to the technical processing and analysis of biological signals; MS and RR obtained funding for this project; SWE and AJES facilitated recruitment and provided clinical input to the project; GPK provided access and guidance on the Finapress technology; RAR and TR developed the analytical plan. All authors participated in the study interpretation, manuscript revisions, and approval of the final version of the manuscript.

\section{CONFLict of InTEREST}

AJES and CLH are shareholders of Therapeutic Monitoring Systems Inc. focused on commercialization of variability-derived clinical decision support tools. AJES and CLH are patent holders of variability monitoring and physiological waveform analysis. All other authors (RAR, SWE, TR, GPK, MS) declare that they have no conflict of interest.

\section{SUPPLEMENTARY MATERIAL}

To view supplementary material for this article, please visit https://doi.org/10.1017/cjn.2020.157.

\section{REFERENCES}

1. Lang EW, Diehl RR, Mehdorn M. Cerebral autoregulation testing after aneurysmal subarachnoid hemorrhage: the phase relationship between arterial blood pressure and cerebral blood flow velocity. Crit Care Med. 2001;29(1):158-63.

2. Rätsep T, Asser T. Cerebral hemodynamic impairment after aneurysmal subarachnoid hemorrhage as evaluated using transcranial 
Doppler ultrasonography: relationship to delayed cerebral ischemia and clinical outcome. J Neurosurg. 2001;95(3):393-401.

3. Otite F, Mink S, Tan CO, et al. Impaired cerebral autoregulation is associated with vasospasm and delayed cerebral ischemia in subarachnoid hemorrhage. Stroke. 2014;45(3):677-82.

4. Kumar G, Shahripour RB, Harrigan MR. Vasospasm on transcranial Doppler is predictive of delayed cerebral ischemia in aneurysmal subarachnoid hemorrhage: a systematic review and meta-analysis. J Neurosurg. 2016;124(5):1257-64.

5. Soehle M, Czosnyka M, Chatfield DA, Hoeft A, Peña A. Variability and fractal analysis of middle cerebral artery blood flow velocity and arterial blood pressure in subarachnoid hemorrhage. J Cereb Blood Flow Metab. 2008;28(1):64-73.

6. Panerai RB, Carey BJ, Potter JF. Short-term variability of cerebral blood flow velocity responses to arterial blood pressure transients. Ultrasound Med Biol 2003;29(1):31-8.

7. Panerai RB. Complexity of the human cerebral circulation. Philos Trans A Math Phys Eng Sci. 2009;367:1319-36.

8. Rickards CA, Tzen YC. Arterial pressure and cerebral blood flow variability: friend or foe? A review. Front Physiol. 2014;5:120.

9. Keunen RWM, Pijlman HC, Visée HF, Vliegen JHR, Tavy DLJ, Stam KJ. Dynamical chaos determines the variability of transcranial Doppler signals. Neurol Res. 1994;16(5):353-8.

10. Ozturk A, Arslan M. Classification of Transcranial Doppler signals using their chaotic invariant measures. Comput Methods Programs Biomed. 2007;86(2):171-80.

11. Ozturk A, Arslan A, Hardalac F. Comparison of neuro-fuzzy methods for classification of transcranial Doppler signals with their chaotic invariant measures. Expert Syst Appl. 2008;34:1044-55.

12. Van den Brule JMD, Vinke EJ, Van Loon LM, van der Hoeven JG, Hoedemaekers CWE. Low spontaneous variability in cerebral blood flow velocity in non-survivors after cardiac arrest. Resuscitation. 2017;111:110-15.

13. Beckers F, Verheyden B, Couckuyt K, Aubert AE. Fractal dimension in health and heart failure. Biomed Tech (Berl). 2006;51(4):194-7.

14. Voss A, Schulz S, Schroeder R, Baumert M, Caminal P. Methods derived from nonlinear dynamics for analysing heart rate variability. Philos Trans A Math Phys Eng Sci. 2009;367(1887): 277-96.

15. Keunen RWM, Vliegen JHR, Stam CJ, Tavy DLJ. Nonlinear transcranial Doppler analysis demonstrates age-related changes of cerebral hemodynamics. Ultrasound Med Biol. 1996;22(4):383-90.

16. Rossitti S, Stephensen H. Temporal heterogeneity of the blood flow velocity at the middle cerebral artery in the normal human characterized by fractal analysis. Acta Physiol Scand. 1994;151(2):191-8.

17. Zhang R, Zuckerman JH, Levine BD. Spontaneous fluctuations in cerebral blood flow: insights from extended-duration recordings in humans. Am J Physiol Heart Circ Physiol. 2000;278(6): H1848-55.
18. Seely AJ, Macklem PT. Complex systems and the technology of variability analysis. Crit Care. 2004;8(6):R367-84.

19. Higuchi T. Approach to an irregular time series on the basis of the fractal theory. Physica D. 1988;31:277-83.

20. Liau BY, Yeh SJ, Chiu CC, Tsai YC. Dynamic cerebral autoregulation assessment using chaotic analysis in diabetic autonomic neuropathy. Med Biol Eng Comput. 2008;46(1):1-9.

21. Grassberger P, Procaccia I. Characterization of strange attractors. Phys Rev Lett. 1983;50(5):346-9.

22. Baselli G, Cerutti S, Porta A, Signorini MG. Short and long-term non-linear analysis of RR variability series. Med Eng Phys. 2002;24(1):21-32.

23. Fisher CM, Kistler JP, Davis JM. Relation of cerebral vasospasm to subarachnoid hemorrhage visualized by computerized tomographic scanning. Neurosurgery. 1980;6(1):1-9.

24. Teasdale G, Jennett B. Assessment of coma and impaired consciousness. A practical scale. Lancet. 1974;2(7872):81-4.

25. Imholz BP, Wieling W, van Montfrans GA, Wesseling KH. Fifteen years experience with finger arterial pressure monitoring: assessment of the technology. Cardiovasc Res. 1998;38(3):605-16.

26. Bos WJ, van Goudoever J, van Montfrans GA, van den Meiracker $\mathrm{AH}$, Wesseling $\mathrm{KH}$. Reconstruction of brachial artery pressure from noninvasive finger pressure measurements. Circulation. 1996;94(8):1870-5.

27. Anderson GB, Ashforth R, Steinke DE, Findlay JM. CT Angiography for the detection of cerebral vasospasm in patients with acute subarachnoid hemorrhage. AJNR Am J Neuroradiol. 2000;21(6):1011-15.

28. Aaslid R. Transcranial Doppler assessment of cerebral vasospasm. Eur J Ultrasound. 2002;16(1-2):3-10.

29. Vergouwen MD, Vermeulen M, van Gijn J, et al. Definition of delayed cerebral ischemia after aneurysmal subarachnoid hemorrhage as an outcome event in clinical trials and observational studies. Stroke. 2010;41(10):2391-5.

30. Gosling RG and King DH. Arterial assessment by Doppler-shift ultrasound. Proc R Soc Med. 1974;67(6 Pt 1):447-9.

31. Zhang R, Zuckerman JH, Levine BD. Deterioration of cerebral autoregulation during orthostatic stress: insights from the frequency domain. J Appl Physiol (1985). 1998;85(3):1113-22.

32. Tzeng YC, MacRae BA. Interindividual relationships between blood pressure and cerebral blood flow variability with intact and blunted cerebrovascular control. J Appl Physiol (1985). 2013;114:888-95.

33. Liu J, Zhu YS, Hill C, et al. Cerebral autoregulation of blood velocity and volumetric flow during steady-state changes in arterial pressure. Hypertension. 2013;62(5):973-9.

34. Zweifel C, Castellani G, Czosnyka M, et al. Continuous assessment of cerebral autoregulation with near-infrared spectroscopy in adults after subarachnoid hemorrhage. Stroke. 2010;41(9): 1963-8.

35. Okamoto K, Horisawa R, Ohno Y. The relationship of gender, cigarette smoking, and hypertension with the risk of aneurysmal subarachnoid hemorrhage: a case-control study in Nagoya, Japan. Ann Epidemiol. 2005;15:744-8. 